\title{
AMBIÊNCIA E MEMÓRIA NA CONSTITUIÇÃO DO HUMANO
}

\author{
Dalva de Souza Lobo*
}

\begin{abstract}
Resumo: As estratégias da memória humana - lembrança e esquecimento, são responsáveis pela preservação da história do homem que, ao longo da existência, procurou aplacar a angústia diante da efemeridade. Dessa forma, ele criou códigos para registrar os eventos ligados à tal preservação, e desses códigos derivaram os conceitos que constituíram seu acervo memorial. Com o passar do tempo, porém, o homem sentiu a necessidade de criar um expediente externo com o qual pudesse partilhar as muitas e diferentes informações do acervo constituído e, assim, ele criou uma memória virtual, viabilizando não somente a troca de informação, mas a possibilidade de articular, para além do tempo e espaço, os signos de sua história. A relação entre memória humana e memória virtual aponta para a consolidação de um novo formato para a aquisição do conhecimento efetivado pelas ranhuras ou rizomas que constituem novos saberes. Neste trabalho, nossa reflexão gira em torno de como essas ranhuras se traduzem ao migrarem entre o espaço da memória humana para a virtual e como criam novos signos que voltam para o humano. Para pensar em que circunstâncias esses fenômenos ocorrem, nos apoiamos nos conceitos de memória, rizoma, territorialização e desterritorialização a partir dos filósofos Henri Bergson, Paul Zumthor, Gilles Deleuze e Félix Guattari. Os resultados obtidos, ainda que provisoriamente, levam à compreensão de que a consolidação entre memória humana e virtual só é possível em função da capacidade humana de, mediante aparato tecnológico, reescrever sua história com base não em uma verdade preestabelecida, mas na interpretação dos fenômenos que levam à criação de signos em constante expansão.
\end{abstract}

Palavras-chave: Memória. Ambiente virtual. Rizoma. Registro.

"O homem nasceu para aprender tanto quanto a vida lhe permita e o sertão, o sertão é o sem lugar, o sertão é do tamanho do mundo". - Riobaldo

\section{Pensando "roseanamente"}

Vejamos, primeiramente, o tamanho do sertão (mundo) e o quanto a vida nos permite aprender e veremos na epígrafe acima uma metáfora do que somos capazes de registrar em nossa memória, do que esquecemos simplesmente para lembrar que mesmo o esquecimento é uma estratégia da memória, é um

\footnotetext{
*Universidade Federal de Santa Catarina. Imeio: dalvalobo@terra.com.br.

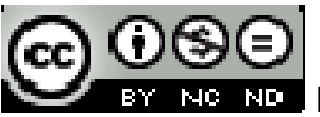

Esta obra foi licenciada com uma Licença Creative Commons
}

Texto Digital, Florianópolis, v. 8, n. 2, p. 114-131, jul./dez. 2012. ISSNe: 1807-9288 
lembrar marginal que, com muito ou pouco esforço, trazemos à superfície como lembrança atualizada.

Pensemos, então, no ambiente-mundo em que Rosa nos convida a apreender o sertão "do tamanho do mundo" e que cabe na exata medida em que a vida nos pertença. Vejamos na imagem do sertão um espaço aberto, cheio de ranhuras, quase que infinito, se levarmos em conta o homem que lá vive e para o qual, certamente, a extensão da terra árida é "o sem lugar", para citar novamente Rosa.

Não se trata, no entanto, de romantizar o agreste. Nossa proposta aqui é lançar um olhar menos árido para as ranhuras da terra e estabelecer com ela e com o "sem lugar" analogias com os ambientes pelos quais a memória humana transita, atravessada por signos que, ao mesmo tempo, remontam a experiências passadas e se esvaem, abrindo espaço para outras ranhuras. Afinal, a memória é cheia de entradas, saídas, veredas e, dada a capacidade humana de perceber a impossibilidade de deter toda essa informação, pode criar uma memória extensiva à sua com a qual partilha experiências e saberes.

É, pois, nessas veredas que vamos registrar nosso percurso em direção às memórias e aos ambientes virtuais ou ambiências ${ }^{1}$ nas quais o início, meio e fim não são propriedades ontológicas, mas perspectivas e, justamente por isso, tornam-se o expediente exterior para nosso registro memorial, permitindo a reconfiguração de nosso modo de perceber o mundo e os artefatos com os quais tecemos nossa história.

Ora, isso ocorre porque a memória remete diretamente a nós mesmos, sujeitos ligados às tradições e aos rituais, entre outras formas de preservação que

\footnotetext{
${ }^{1} \mathrm{O}$ termo ambiência aqui é utilizado de acordo com o conceito criado pelo professor e poeta Wilton Azevedo para designar um ambiente no qual a escritura poética se expande em função das inúmeras articulações advindas das experimentações e mutações dos códigos em constante migração, sem necessidade de uma matriz para seu registro, já que transitam num espaço em que a relação tempo e espaço se faz parataticamente e em mutação constante, uma experiência que não se preocupa em criar fórmulas"(AZEVEDO, 2009, p. 103-105).
} 
minimizam nossa angústia diante da efemeridade e, também, pela profunda força e potência que essa memória tem de nos levar a criar espaços em que podemos de modo cada vez mais sofisticado, enveredar e fazer enredar nossas experiências.

Lidar com a memória implica lidar com o esquecimento, sua contrapartida ou continuum, e, entre ambos - memória e esquecimento - se situam os fragmentos decorrentes da seleção feita pela memória e que se dilata nesse sem lugar entre memória e esquecimento como lembrança. Esta, ao trazer os dados do acervo memorial, aos quais atualiza, daí ser então a lembrança, essencialmente individual, pois mesmo que várias pessoas se lembrem de um evento, cada uma vai trazê-lo de acordo com sua percepção.

A memória integra os sentidos por meio de uma arquitetura sinestésica interpenetrando sons, silêncios, imagens, gestos e odores sem relação preestabelecida entre eles e, dessa forma, levam a diferentes sensações. Um exemplo dessa interpenetração é a imagem de alguém suscitada pelo som de sua voz ou pelo perfume. Ao fazê-lo, trazemos à lembrança sentimentos ligados a tal pessoa ou à determinada situação vivenciada, mas aqui a lembrança já é uma atualização do evento experimentado, o qual ficou arquivado em nosso acervo memorial e do qual selecionamos um ou mais fragmentos em detrimento de outros que legamos ao esquecimento.

Memória, lembrança e o esquecimento estão dinamicamente conectados, sendo a lembrança e o esquecimento decorrentes da memória da qual emergem e para a qual retornam num ciclo que permite expandir o que chamamos de experiência e esse continuum tem a ver com a elasticidade dessa conexão não hierárquica e constantemente ressignificada por novas experiências.

Se a memória é da ordem da tradição, da preservação e a ela se ligam esquecimento e lembrança como estratégias ou veredas, considerando que ela 
seja o espaço das ranhuras que mencionamos acima, a forma como essas ranhuras se constroem no ambiente virtual é a inquietação que conduz nossa reflexão. Para consolidá-la, nos apoiaremos nos conceitos sobre memória, lembrança e esquecimento do filósofo Henri Bergson e do poeta medievalista e pesquisador da voz, Paul Zumthor, tendo em vista a proximidade estabelecida por ambos em relação à conexão dinâmica entre os três movimentos.

Para Bergson, a memória compreende uma fonte constante de atualização de experiências vividas com as quais o homem coexiste na medida em que passado e presente são interfaces dessas experiências e "essencialmente virtual, o passado não pode ser apreendido por nós como passado, a menos que sigamos e adotemos o movimento pelo qual ele se manifesta em imagem presente" (BERGSON, 2006, p. 49). Ou seja, o passado só pode ser atingido quando manifestado pela memória como tempo presente.

Quanto a Paul Zumthor, a memória implica um saber coletivo, ligado à preservação de laços sociais atualizados através de rituais para assegurar as tradições, sobretudo as de fatos ligados à cultura oral, visto que para o poeta tradição e memória são da ordem da coletividade na medida em que instituem modelos, padrões de comportamento mantendo a coerência, já que "a memória do grupo tende assegurar a coerência de um sujeito na apropriação de sua duração: gera a perspectiva em que se ordena uma existência e, nesta medida, permite que se mantenha a vida" (ZUMTHOR, 1997, pp. 13-14).

Além disso, para Zumthor (1997, p. 16), esquecimento tem a ver com desejo, com retorno à dinâmica da vida em seu movimento presente, pois 0 esquecimento "não anula, ele poli (sic), apaga, e, por isto, clarifica o que deixa à lembrança, transformando-a em tipo, extraindo daquilo que foi sua fragilidade temporal, sua incômoda primeira fugacidade", e, nesse sentido opera a atualização dos eventos passados. 
Sobre o ambiente virtual, sobretudo no que toca ao conceito de rizoma ${ }^{2}$ e aos princípios de territorialização e desterritorialização ${ }^{3}$ recorrentes nessa trajetória, nos apoiaremos nos estudos dos filósofos Gilles Deleuze e Félix Guattari. O rizoma é um termo extraído da botânica para identificar tipos de brotos que não crescem no sentido arborescente e hierárquico, mas desordenadamente em relação a qualquer princípio dicotômico ou unificado, podendo ser uma raiz ou um bulbo; por isso pode nascer em qualquer lugar e expandir-se para outro sem necessidade de um movimento hierárquico, como a grama, por exemplo. $\mathrm{Na}$ concepção de Deleuze e de Guattari, o rizoma remete ao descentramento da noção de início, meio e fim lineares, pois

\begin{abstract}
O rizoma conecta um ponto qualquer com outro ponto qualquer e cada um de seus traços não remete necessariamente a traços da mesma natureza; ele põe em jogo regimes de signos muito diferentes. Ele na tem começo nem fim, ma sempre um meio pelo qual cresce e transborda. O rizoma é um sistema acentrado não hierárquico e não significante. Sem General, sem memória organizadora, unicamente definida por uma circulação de estados. (DELEUZE; GUATTARI, 1995, pp. 32-33)
\end{abstract}

Assim como o rizoma, a memória não opera por dicotomias e nem por meio de Generais, isto é, sem a memória organizada de forma arborescente, por isso expande-se e dilata-se nos movimentos de lembrança e de esquecimento. Nesse sentido, são implicados os princípios de territorialização e desterritorialização. Ambos são característicos do rizoma e podemos relacionálos à lembrança e ao esquecimento visto que também operam com linhas de sedimentação (lembrança e atualização) e de fuga (esquecimento) em um continuum, pois em cada movimento também se inclui a reterritorialização a

\footnotetext{
${ }^{2}$ Segundo Deleuze e Guattari "o rizoma nele mesmo tem formas muito diversas, desde sua extensão superficial ramificada em todos os sentidos até suas concreções. Um rizoma não cessaria de conectar cadeias semióticas, organizações de poder, ocorrências que remetem às artes, às ciências, às lutas sociais. Cada cadeia semiótica é como um tubérculo que aglomera atos muito diversos, linguísticos, mas também perceptivos, mímicos, gestuais, cogitativos. Um método do tipo rizoma é obrigado a analisar a linguagem efetuando um descentramento sobre outras dimensões e outros registros." (DELEUZE; GUATTARI, 1995, p.15-16).

${ }^{3}$ Ligados ao rizoma sendo que este compreende linhas de segmentaridade segundo as quais ele é estratificado, territorializado, organizado, significado, atribuído, etc., mas também compreende linhas de desterritorialização pelas quais ele foge sem parar. (IDEM, p.18)
} 
partir da qual, outra desterritorialização se processa - (daí, a relação da memória como presente, passado e devir interpenetrados).

\title{
2. Memória e registro
}

\author{
"A memória é a primeira realidade do \\ espírito, a partir da qual se originam 0 \\ pensar e o querer." - Santo Agostinho
}

Desde sempre, o homem buscou formas de registrar sua história no intuito de preservá-la e, ao mesmo tempo, disseminá-la. Daí os rituais e os mitos cujos ensinamentos eram passados de geração em geração, como mostram as culturas orais, em que a voz era mais do que mediadora de saberes, ela mesma se constituía como signo em torno do qual se cristalizavam laços sociais e culturais.

Na voz, a palavra enuncia-se como lembrança, memória-emato de um contato inicial, na aurora de toda vida e cuja marca permanece em nós um tanto apagada, como a figura de uma promessa. Cada sílaba é sopro, ritmado pelo batimento do sangue; e a energia deste sopro, com o otimismo da matéria, converte a questão em anúncio, a memória em profecia, dissimula as marcas do que se perdeu e que afeta irremediavelmente a linguagem e o tempo. Por isso a voz é palavra sem palavras, depurada, fio vocal que fragilmente nos liga ao Único. (ZUMTHOR, 2010, p. 12)

A enunciação da voz através da lembrança ocorre porque, entre esta e a memória, há um continuum, ou seja, um processo decorrente da capacidade de, sempre presente, a memória dilatar-se em pequenos fragmentos aos quais chamamos lembrança e com a qual ela, a memória estabelece uma conexão dinâmica.

Assim, culturas foram fundadas e incorporadas umas às outras devido às guerras entre os povos. Através do acúmulo dos saberes e dos costumes, o homem pode compreender os fenômenos da natureza e da própria existência, o que, de certo modo, o ajudou a aplacar a angústia da efemeridade mediante 
a lembrança e o esquecimento, movimentos contínuos que se estenderam da memória humana para o ambiente virtual.

O acervo memorial humano, o qual podemos acessar em função desse ambiente para articular os códigos verbais e os não-verbais, modificou a maneira como lidamos com o registro e com o conhecimento. Se lembrança e esquecimento são movimentos contínuos da memória humana, quando se trata de ambiente virtual, esses movimentos são dinamizados devido à relação tempo-espaço que se faz como presentidade ${ }^{4}$.

Sobre a presentidade, cabe dizer que ela é da ordem do cotidiano, da imediateidade que trazemos das reminiscências da memória, das sensações corpóreas e sem qualquer lastro temporal, a não ser o do instante em que as atualizamos mediante a lembrança. Ora, a lembrança se estende ao corpo através dos suores, angústias, silêncios e outros elementos que antes estavam na virtualidade da memória. Graças à lembrança, podem ser reconfigurados entrelaçando passado, presente imediato e devir. Algo que escapa ao sentido cronológico de tempo e dilui a distância entre o sujeito e a experiência, pois cada sensação é uma experiência única e seu espaço é o do aqui e agora da presentidade.

Há tempos a memória deixou de ser exclusividade humana, ao contrário da lembrança, que é essencialmente uma característica humana, já que lida com sentimentos e sensações corpóreas. A memória, por sua vez, criou outro expediente para armazenar informações e isso implicou novos recortes epistemológicos e nova compreensão sobre a produção e aquisição de conhecimento, pois, além de armazenar códigos em documentos arqueológicos e historiográficos, passamos a redimensioná-los graças aos sofisticados

\footnotetext{
${ }^{4}$ Segundo Charles Sanders Peirce, a categoria de presentidade remete ao presente (imediato) e é o que é, não determinado pelo ausente, passado e futuro. É como tal, ignorando totalmente qualquer outra coisa (...) qualquer qualidade de sensação, simples e positiva, preenche nossa descrição daquilo que é tal como é, absolutamente sem relação com nenhuma outra coisa. "Qualidade de sensação" é a verdadeira representante psíquica da primeira categoria do imediato em sua imediatidade, do presente em sua presentidade. (PEIRCE, 1980, p. 18).
} 
sistemas que nos permitem, inclusive, prescindir do contato presencial para efetivar a comunicação.

Isso não quer dizer que o contato presencial seja menos importante. Ao contrário, é a partir da interface entre homem e máquina que, mais do que nunca, atestamos nossa capacidade de atualizar os signos de nossa história, na medida em que lidamos com a temporalidade e com a espacialidade de forma mais dinâmica, levando em conta que essas máquinas e esses softwares fazem parte de um ambiente virtual no qual a noção espaço-temporal não se faz necessariamente de forma linear.

Parafraseando as palavras de Santo Agostinho sobre a memória "ser a primeira realidade do espírito a partir da qual se originam o pensar e o querer" (LAUANDI, 1998, p. 9-10), é pertinente dizer que no ambiente virtual eles são potencializados e alteram nossa forma de comunicação e de registro através de uma atividade interdisciplinar, já que o acesso ao conhecimento nesse ambiente é possível ao mundo todo.

Tomemos a expressão ambiente virtual a partir da palavra virtual (do latim virtualis, ou seja, força, potência), na qual está implicado o "sem-lugar", ou, o lugar passível de preenchimento e, por isso, não cristalizado. A memória também pode ser vista como virtual, pois seus dados ficam em suspenso até que os tomemos por meio da lembrança. Nesse sentido, podemos dizer que tanto a memória humana quanto a máquina operam virtualidades, embora a máquina dependa de uma programação para constituir o arquivo de memórias e não leve em conta afetos, angústias e demais sentimentos e sensações característicos do humano e do processo de atualização decorrente da lembrança.

A memória humana tem a ver com a experiência sendo, ao mesmo tempo, passiva e ativa. Passiva enquanto memória territorializada, sedimentada pelos signos que constituem seu acervo, e aí estamos falando de tradição, de coletivo. E ativa na medida em que, por meio da lembrança, desterritorializa, 
isto é, traça linhas de fuga, escapa à regra, ao conjunto de costumes e tradições e atualiza os signos de forma individual, posto que cada corpo tem sua maneira de manifestar sentimentos e fazer despertar sensações. Nesse caso, estamos falando, também, do fluxo de consciência derivada da lembrança e da percepção que é inerente a ela e se mostra diferente para cada pessoa.

Ora, retomando a palavra virtual do ponto de vista da memória humana notamos, então, que enquanto virtualidade, ela opera esquecimento e lembrança de forma diferente da memória virtual em função do engajamento corporal. Quando retemos e esquecemos dados, estamos, na verdade, liberando espaço para que o novo se insinue e se constitua e, ao fazê-lo por meio de ambiente virtual, operamos lembrança, esquecimento, tradição e fugacidade simultaneamente.

\section{Memória humana (biológica) e memória digital: tradição e fugacidade}

Sem nos deter em explicações mais aprofundadas, julgamos ser interessante, nesse momento, apontar algumas diferenças e aproximações entre as duas formas de memória para compreender como se dá a construção das ranhuras, a inquietação apontada no início deste ensaio.

Comecemos por examinar o que ambas têm em comum: a complexidade na forma de redimensionar o acervo sígnico que as compõem. Ambas operam com esquecimento, tradição e fugacidade. Todavia, cada qual a seu modo e é exatamente essa diferença na operacionalização que as aproxima, deixando claro que a compreensão da coexistência de ambas é fundamental para nossa reflexão acerca do mundo no qual estamos inseridos.

Enquanto o acervo memorial humano cria conceitos (formando e enformando) sobre os eventos e os articula com outros já constituídos e dos quais participam os sentimentos e as sensações, a memória do ambiente virtual apenas armazena os dados definidos que compõem seu acervo de 
informações. Estas são acionadas de acordo com o desejo humano e, se esse ambiente simula algumas sensações, não se pode compará-las ao humano por serem simples simulações pré-programadas. Todavia, mesmo as informações e simulações memorizadas no computador são significativas na medida em que buscam se aproximar do simbólico humano, inclusive da linguagem e é nesse sentido que nos auxiliam a compreender e a preservar nossa história.

A memória humana, como já mencionado, lida com estratégias para reorganizar os eventos e absorver novas significâncias e significantes, e isso tem a ver com o aspecto histórico tão caro à preservação dos costumes e tradições dos diferentes povos, o que remete à virtualidade do passado atualizado como lembrança, como apontou Bergson:

Essas tradições são suscitadas pela lembrança de um passado profundamente enraizado em relação ao qual devemos nos colocar como atualizadores, pois, "essencialmente virtual, o passado não pode ser apreendido por nós como passado, a menos que sigamos e adotemos o movimento pelo qual ele se manifesta em imagem presente" O passado só pode ser atingido quando manifestado pela memória, porque nesta se assenta o dizer social e cultural dos povos. (BERGSON, 2006, p. 49)

que Bergson mostra é o autodescentramento do inconsciente ou do individual para o coletivo - cultura - em função da percepção sobre os acontecimentos a partir da atualização, isto é, da presentidade que acolhe os fenômenos e os signos culturais dos quais derivam novos saberes, e novas formas de aquisição de conhecimento. Ainda citando Bergson,

De fato, não há percepção que não esteja impregnada de lembranças. Aos dados imediatos e presentes de nossos sentidos misturamos milhares de detalhes de nossa experiência passada. Em geral, essas lembranças deslocam nossas percepções reais, das quais não conservamos então mais que algumas indicações, simples sinais destinados a nos lembrar antigas imagens. (BERGSON, 2006, p. 86). 
Ao atualizar determinado evento através da lembrança ocorre a interface entre a realidade presente, o tempo passado e o devir em função do continuum, ou seja, da extensão decorrente do vínculo entre lembrança e memória e que se traduz nos movimentos do corpo ${ }^{5}$, o qual participa ativamente do processo de aquisição de conhecimento a ser incorporado no acervo memorial humano, tanto no aspecto individual quanto no coletivo. É importante dizer, também, que desse corpo insurge a voz, aqui compreendida como voz em performance ${ }^{6}$, tendo em vista que ela, como forma de registro, é uma das mais relevantes no que toca aos sons que emanam do corpo, como apupos, gritos, sussurros e outros que extrapolam o corpo para manifestar sentimentos e sensações.

As emoções mais intensas suscitam o som da voz, raramente a linguagem: além ou aquém desta, murmúrio e grito, imediatamente implantados nos dinamismos elementares. Grito natal, grito de crianças (...) voz plena, negação de toda redundância, explosão do ser em direção à origem perdida ao tempo da voz sem palavra. (ZUMTHOR, 2010, p. 11).

Vemos também o continuum entre esquecimento e lembrança junto à necessidade ou impossibilidade de controlar o tempo, tendo em vista que este é constante devir entrelaçado ao presente imediato e ao passado. Em se tratando de ambiente virtual, esse continuum é colocado em funcionamento devido ao afrouxamento do laço espaço-temporal, e, sem a perspectiva de início, meio e fim, se rizomatiza, levando os signos a uma reconfiguração.

Ao criar um ambiente extensivo à memória humana, passamos a confiar parte de nosso acervo histórico, cultural e social com o intuito não apenas de preservá-los, mas de tramar os nós entre passado, presente e devir mediante a intersecção de códigos verbais e não verbais, a exemplo da arte poética da

\footnotetext{
${ }^{5}$ Os movimentos do corpo são compreendidos aqui como performance e podem remeter à voz na medida em que esta é uma forma de registro que entrelaça memória, corpo, sentimentos e sensações.

${ }^{6}$ A Voz em performance é compreendida como engajamento entre a memória e o corpo, do qual ela se esvai como manifestação para além de taxonomias de ordem de tradição linguística, já que envolve sons muitas vezes não previstos pelas figuras de linguagem, sobretudo em se tratando de voz poética;
} 
voz, que cada vez mais vem transformando nossa percepção sobre a criação dos artefatos com os quais podemos interagir quase como coautores.

Em se tratando de fruição dos objetos poéticos, ela não se aplica ao ambiente virtual, embora, sem dúvida, participe do processo de criação e é nesse sentido que ambiente virtual e memória se aproximam do querer e do pensar conforme afirmou Santo Agostinho "a memória é a primeira realidade do espírito, a partir da qual se originam o pensar e o querer", pois já não se trata mais de somente manter o registro, mas de modificá-lo a ponto de colocar em cheque a própria epistemologia.

$\mathrm{Na}$ criação artística em mídia digital, por exemplo, a articulação de códigos estabelece no mínimo uma interface: a do artista com o software utilizado e que por si só, já se define como parte do processo da criação artística. Além disso, nesse exercício de criação e de experimentação rompe com a necessidade de códigos matriciais isolados, implicando uma nova postura diante da produção de significados.

No ambiente virtual os códigos passam a migrar sem a necessidade de estabelecer vínculo com um lugar a não ser o do momento, algo semelhante à atualização feita pela lembrança e responsável pela não cristalização devido à experimentação constante. Ou seja, "no sem lugar" em que se formam as ambiências nas quais os códigos se entrecruzam sem necessidade de se fixar, o que leva a criação de novos signos também em devir, posto que se atualizam constantemente.

Esse movimento tem a ver com aquilo que os filósofos Deleuze e Guattari denominaram de Corpo sem órgãos ( $\mathrm{CsO}$ ),

um CsO é o campo de imanência do desejo, o plano de consistência própria do desejo (ali onde o desejo se define como processo de produção, sem referência a qualquer instância exterior, falta que viria a torná-lo oco, prazer que viria a preenchê-lo". ( DELEUZE; GUATTARI, 1996, p. 15). 
O ambiente virtual seria, de acordo com o $\mathrm{CsO}$, o campo da imanência e, portanto, campo das heterogeneidades e da produção de novos significados que passam a integrar nosso acervo memorial numa relação de constante territorialização e desterritorialização ou, mais especificamente, constante processo de organização e ruptura a partir dos quais atualizamos nossos signos em diferente contextos.

\begin{abstract}
A territorialização e a desterritorialização são características do rizoma e estão ligadas ao "princípio de ruptura a-significante do rizoma: contra os cortes demasiado significantes que separam as estruturas". Todo rizoma compreende linhas de segmentaridade segundo as quais ele é estratificado, territorializado, organizado, significado, atribuído, etc.; mas compreende também linhas de desterritorialização pelas quais ele foge sem parar (DELEUZE; GUATTARI, 1995, p. 18)
\end{abstract}

A territorialização implica a organização dos fragmentos das experiências constantes do acervo da memória humana, ou seja, ela tem a ver com a sedimentação dos signos da cultura e da sociedade, sendo, portanto, da ordem do coletivo ao qual incorporamos nossa memória individual. Já a desterritorialização desestabiliza essa suposta organização ao reordenar e rearticular tais fragmentos trazidos para a consciência e para o corpo e, quando ocorre a migração para o ambiente virtual, esses fragmentos são potencializados formando as ambiências nas quais se reconfiguram como devires.

Nessas ambiências os fragmentos são potencializados devido ao rompimento da relação espaço-temporal, ou seja, devido à presentidade que os integra, exclui, modifica e os coloca em constante movência, e essa característica aponta para uma diferença e ao mesmo tempo uma semelhança entre memória virtual e memória humana que é a forma de lidar com a tradição e a fugacidade.

Ocorre, como apontou Hume, que "a repetição nada muda no objeto que se repete, mas muda alguma coisa no espírito que a contempla (HUME apud 
DELEUZE, 2006, p. 111), ou seja, embora ambas as memórias lidem com a atualização de dados de seu acervo, somente à humana pertence a lembrança, que, como já vimos, leva em conta sentimentos e sensações, algo que a memória virtual não pode contemplar, a não ser como simples simulação, já que não lida com engajamento corporal.

Em se tratando de memória virtual, a tradição é retomada como índice de movência, já que não se trata de preservar, mas de articular os signos da tradição visando sua inovação.

Podemos pensar no sistema de código linguístico, extremamente rico e importante para a comunicação, mas, quando articulado para além da tradição imposta pela gramática, que busca a combinação fonética, por exemplo, para evitar ruídos, pode resultar em outra forma de fruição estética. É o caso de privilegiar o som sobre a ortoépia; a articulação sonora não privilegiada pela sintaxe de tradição linguística provoca outras sensações no ouvinte, principalmente se este puder participar da experiência, isto é, se ele for o agente provocador dessa desterritoralização.

\section{1 - Tradição e fugacidade em diálogo}

Partindo do princípio de que o ambiente virtual é o espaço ao qual confiamos nosso acervo histórico, cultural e social, ou seja, nossa memória, ao redimensionar os signos nesse mesmo espaço, permitindo sua modificação a partir da formação de ambiências, cuja prerrogativa é a não linearidade, propomos a preservação da história a partir da qual podemos atualizar os signos ao articular presente, passado e devir.

No entanto, não garantimos mais sua fidedignidade no tocante à formação, visto que nessas ambiências o acesso não ocorre no sentido espaço-temporal hierarquizado, e por isso prescindirem de uma única forma de registro para sua materialidade, enriquecem a reflexão sobre o sentido de criação, uma das características mais significativas do homem. 
As bibliotecas e os museus sempre foram por excelência os guardiões de nossa história, cujos documentos físicos representam nossa memória, mas essa materialidade está sendo preservada também graças aos expedientes criados,em vista dos quais além de armazenar, podemos refletir sobre tudo o que nos diz respeito sem nos limitarmos a uma matriz de registro.

Nesse contexto, surgem novas possibilidades de rever a história através da rizomatização dos signos que migram por diferentes espaços, o que é enriquecedor, se consideramos que a intersecção entre códigos independe de uma matriz para seu registro e que articulação significativa se traduz na constante presentidade, permitindo compreender os artefatos que compõem o acervo humano para além da relação diacrônica.

Poderíamos estudar, obviamente, os documentos e acervos estabelecendo relações entre eles, porém, não de forma tão ágil como o fazemos quando dispomos de um aparato cuja memória não carrega o mesmo peso histórico que a humana.

E, se por um lado, essa nova relação com a aquisição do conhecimento pode causar desconforto em relação à garantia de preservação, tendo em vista que não podemos precisar se a informação estará ou não disponível após um determinado tempo, em função do poderíamos chamar metaforicamente de "esquecimento da máquina", por outro lado, é notável a quantidade de armazenamento possível nesses ambientes e, mais importante, o quanto tornam acessíveis as informações para todos ao redor do mundo. Isso ocorre porque o "esquecimento da máquina", não tem a ver senão com um ato que não remete ao engajamento corporal, ou seja, aos sentimentos e sensações, como ocorre com a lembrança, a qual é essencialmente humana.

É notável a quantidade de armazenamento possível nos ambientes virtuais e o quanto se tornam acessíveis as informações para todos ao redor do mundo, a exemplo do aprendizado, no qual podemos notar uma significativa modificação 
em relação às pesquisas, hoje acessíveis de qualquer lugar e a qualquer pessoa. Na verdade, o ambiente virtual acaba por preservar nossa história e cultura justamente por não ter "a preocupação" de eternidade, ou seja, é no efêmero do aqui e do agora que ele reafirma a tradição tão cara à memória humana. E, nesse sentido, corrobora que tempo e espaço são apenas dimensões para nos situarmos, já que "O tempo e o espaço são modos pelos quais pensamos e não condições nas quais vivemos", como dizia o cientista Albert Einstein.

Ao rearticular e inovar os signos que trazemos desde os primórdios do que conseguimos registrar em documentos arqueológicos, à exceção da fala, pois dessa os registros são ainda insuficiente, o ambiente virtual utiliza em sua composição códigos disponibilizados pelo homem com os quais gera outros, ou seja, novo e antigo em constante diálogo. Nada pode ser mais humano.

Preocupações acerca da imediatidade e da superação do homem pela máquina entre outras são recorrentes, pois, mais do que nunca, nos deparamos com aparatos tecnológicos cada vez mais sofisticados. Assim, sem dúvida, hoje, não se pode pensar em memória sem esses aparatos. Porém, inscrita no centro dessa realidade, mais concreta de que nunca, está a figura humana em sua contemporaneidade e num tempo e espaço construídos por ela e que podem ser modificados a seu favor atestando as condições humanas mais evidente: o inacabamento e a heterogeneidade.

Retomando Riobaldo, personagem de Grande Sertão: Veredas,

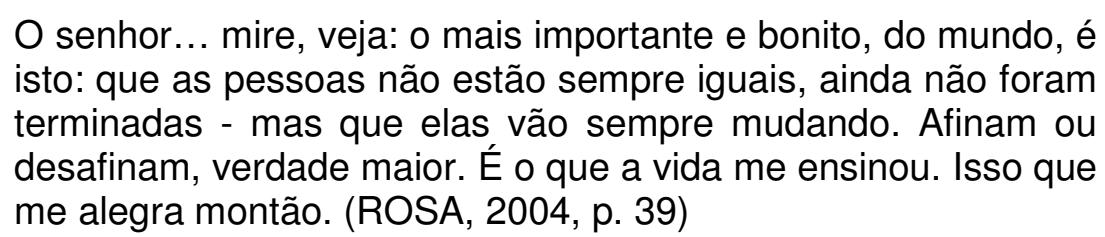

O que ele nos diz vai ao encontro do que temos discutido aqui: a condição de inacabamento e heterogeneidade tem a ver com a inconstância e com a 
diversidade de nossa memória e dos ambientes que criamos para lidar com nossa humanidade e com nossa forma de nos relacionar com o outro e com o mundo.

São as aporias, as inconstâncias, e não as certezas que nos fazem caminhar e constantemente criar, recriar ou "demudar" como diria Riobaldo. E todos esses percursos constituem o acervo memorial no qual buscamos ranhuras formando no constante "sem lugar" as ambiências para acolher nossa finitude e da qual, sem dúvida, faz parte o novo - compreendido na esfera ao ambiente virtual enquanto memória e campo de imanência dos desejos que nos aferem condições de lidarmos com o novo, sem esquecer o diálogo com o "antigo" se quisermos chamar assim, nossos ancestrais e nossas tradições.

E o fato de não estarmos prontos, terminados, e de desafinarmos só confirma nossa homogeneidade, e isso, por si só, já é suficiente para alegrar montão" pois aponta para a infinita capacidade humana de aprender, sobretudo, quando se percebe atuando com um outro aparato a partir do qual pode rever, reescrever e compreender os artefatos desse mundo não como verdade preestabelecidas sobre ele mas como interpretações de sua história, ou de sua humanidade.

\section{AMBIENCY AND MEMORY IN THE HUMAN CONSTITUTION}

ABSTRACT: The strategies of the human memory - remembrance and forgetfulness, are responsible for the preservation of the mankind history, who has tried to cease the anguish created by frailty. Because of this, man has brought up some codes in order to register the events connected to such preservation and that is where all the concepts that are part of this collection of memories come from. As time has gone by, however, man has believed it was necessary to create an external expedient, in which the many different information from this collection might be shared. Then, he created a virtual memory, making possible not only the information exchange, but also the possibility of articulating the signs of his history to beyond time and space. The relation between human and virtual memories points to the consolidation of a new format for knowledge acquisition effected by grooves or rhizomes that are part of new knowledges and our reflection revolves around how these grooves are translated when they migrate from the human memory to the virtual one, and how to create new virtual signs that come back to the human's. In order to think about the circumstances in which this occurs, we considered the concepts of memory, rhizome, territorialization and deterritorialization from the philosophers Henri Bergson, Paul Zumthor Gilles Deleuze and Félix Guattari. The results, yet temporary, lead to understand that the consolidation between human and virtual memory is only possible due to the human being capacity of rewriting his history based on the interpretation of 
the phenomena that lead to the creation of signs in constant expansion. And all this would only be possible with the help of a technological apparatus.

KEYWORDS: Memory. Virtual environment. Rhizome. Register.

\section{Referências}

ABAGNANO, Nicola. Dicionário de Filosofia. $5^{\underline{a}}$ ed. São Paulo: Martins Fontes, 2007.

AZEVEDO, Wilton. Interpoesia: o início da escritura expandida. Tese de PósDoutorado. Paris: Laboratoire de Paragraphe, 2009.

BERGSON, Henri. Memória e Vida. Textos escolhidos por Gilles Deleuze. Trad. Claudia Berliner. São Paulo: Martins Fontes, 2006.

O pensamento e o movente: ensaios e conferências. Trad. Bento Prdo Neto. São Paulo: Martins Fontes, 2006.

Matéria e memória. Rio de Janeiro: M. Fontes, 1999.

DELEUZE, Gilles; Guattari, Félix. Mil Platôs: capitalismo e esquizofrenia. vol. 3. Trad. Aurélio Guerra Neto et alii. Rio de Janeiro: Ed. 34, 1996.

. Mil platôs: capitalismo e esquizofrenia. vol.5 Trad. Peter Pál Pelbart; Janice Caiafa. Rio de Janeiro: Ed. 34, 1995.

DELEUZE, Gilles. Diferença e Repetição. Trad. Luiz Orlandi, Roberto Machado. 2ª Ed. Rio de Janeiro: Graal, 2006.

LAUANDI, Luiz Jean Lauand (org. e trad.). Cultura e educação na Idade Média: textos do século V ao XIII. São Paulo: Martins Fontes, 1998.

ROSA, João Guimarães. Grande Sertão: Veredas. 19 ed. Rio de Janeiro: Nova Fronteira, 2001. Perspectiva, 2010.

Semiótica. Trad. José Teixeira Coelho Neto. São Paulo:

ZUMTHOR, Paul. Tradição e esquecimento. Trad. Jerusa Pires Ferreira e Suely Fenerich. São Paulo: Hucitec, 1997.

Texto recebido em 05/11/2012. 